\title{
Absolute isolated avulsion of the anterolateral complex of the knee: a segond fracture
}

\begin{abstract}
The authors report a case of knee trauma in a 24-year-old woman. The X-ray showed a Segond's fracture: an avulsed bone fragment, lying immediately below the joint line of the lateral tibial plateau, dislocated a few millimeters from the lateral tibial cortex. The fracture site was related to the site of anterolateral ligament (ALL) and iliotibial band (ITB) tibial attachment. Clinical examination revealed anterolateral instability of the knee. Magnetic resonance image (MRI) and subsequent arthroscopy revealed an isolated ALL lesion. All other strictures were intact: anterior cruciate ligament (ACL), posterior cruciate ligament (PCL), medial collateral ligament (MCL), postero-lateral corner (PLC) and meniscus. The author reports an isolated Segond fracture in adult
\end{abstract}

Keywords: segond fracture, anterolateral ligament, knee, avulsion fracture
Volume I Issue 6 - 2017

\author{
Marcio de Castro Ferreira, Flavio Ferreira \\ Zidan, Francini Belluci Miduati, Caio \\ Cesar Fortuna, Carlos Eduardo da Silveira \\ Franciozi, Rene Jorge Abdalla \\ Department of Ortopedics, Hospital do Coração-Hcor, Brazil
}

Correspondence: Marcio de Castro Ferreira, Department of Ortopedics, Hospital do Coração-Hcor, Brazil,Tel 305366 I I, Email marciojoelho@gmail.com

Received: October II, 2017 | Published: December 20, 2017
Abbreviations: ALL, anterolateral ligament; ITB, iliotibial band; MRI, magnetic resonance image; ACL, anterior cruciate ligament; PCL, posterior cruciate ligament; MCL, medial collateral ligament; PLC, postero-lateral corner

\section{Introduction}

The Segond fracture is defined as an avulsion of the proximal anterolateral tibial plateau region originally described by the French surgeon Paul Ferdinand Segond in 1879.1,2 This injury is widely accepted as a pathognomonic radiographic marker of anterior cruciate ligament (ACL) injury. ${ }^{1-3}$ However, some reports describe this injury in the presence of an intact ACL in skeletally immature patients. ${ }^{4-5}$ Recent anatomical and histological studies had described the anterolateral knee ligament (ALL).$^{6-9}$ This structure defined by Dr. Segond initially in the nineteenth century has been receiving different nomenclatures until recently be assigned as ALL. ${ }^{10}$

Proximally, the ALL originates near the lateral femoral epicondyle and inserts distally on the lateral meniscus and the anterolateral tibial edge, halfway between Gerdy's tubercle and the fibular head. This is the exact site of the Segond fracture according to a study by Claes et al. ${ }^{12}$ describing ACL injuries associated with this type of avulsion..$^{6-11}$ A retrospective MRI analysis of ACL injuries indicated changes in the ALL images in $78.8 \%{ }^{12}$ The purpose of this case report is to demonstrate an isolated Segond fracture coursing with anterolateral knee instability without ACL neither other knee ligament injuries in an adult patient. The lesion was surgically treated presenting good results at two years follow-up.

\section{Case report}

A 24-year-old female suffered a knee sprain after being hit by a motorcycle at low speed. She complained of lateral proximal pain in her right leg at her first medical visit. After performing X-rays, the informed diagnosis at her first evaluation at other service was contusion of the proximal leg. The leg was immobilized for two weeks followed by rehabilitation. Three months after the accident, she came to our outpatient clinic complaining of pain and instability of the right knee presenting frequent giving away episodes. During the clinical examination, she presented normal gait and normal range of motion. The Lachman test showed slight anterior translation with a firm endpoint as well as the anterior drawer test when compared to the normal side, being both classified as grade B (nearly normal). The pivot-shift test was positive and classified as grade $\mathrm{C}$ (abnormal). ${ }^{13}$ The Lysholm scale ${ }^{14}$ applied questionnaire score was rated as poor (43 scores).

Knee radiographs revealed the Segond fracture (Figure 1A) (Figure 1B). The patient underwent an MRI and a computed tomography (CT). Both CT and MRI showed the Segond fracture. The MRI showed integrity of the ACL, posterior cruciate ligament (PCL), medial collateral ligament (MCL), posterolateral corner (PLC) structures and menisci (Figure 2A-2E).

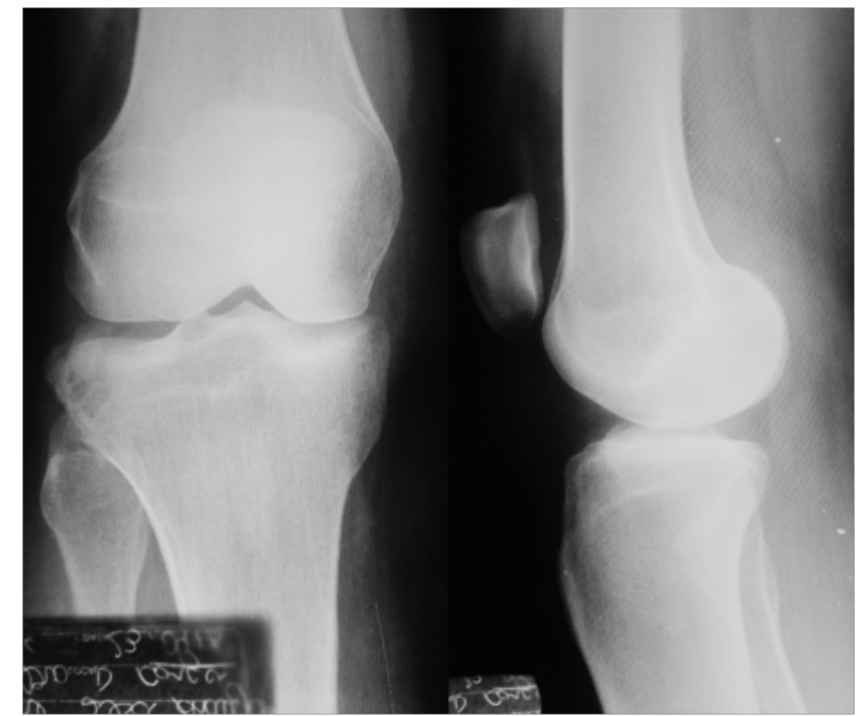

Figure I (A) Anteroposterior radiography demonstrating the Segond fracture. (B) Lateral radiograph

The authors opted for surgical treatment due to frequent instability complaints and the presence of the Segond fracture. In addition, the patient had not improved after three months of conservative 
treatment involving muscle strengthening and proprioception at the physiotherapy. Physical examination after anesthesia was not different from the one obtained before it. An arthroscopy inspection was performed confirming ACL integrity and no intra-articular lesion (Figure 2F). A $12 \mathrm{~cm}$ curvilinear lateral approach was performed to address the Segond fracture. It started $3 \mathrm{~cm}$ proximal to the femoral lateral epicondyle and extended distally halfway between the Gerdy's tubercle and the fibular head around $3 \mathrm{~cm}$ distal to the joint line. The bone fragment was considered inappropriate for fixation. It was thin and small, and the lateral structures attached to it, the ALL and/or the anterolateral capsule, were irreversibly proximally retracted impairing its anatomical fixation. The bone fragment was resected and an extraarticular reconstruction was performed with the iliotibial band (ITB) preserving its tibial insertion on Gerdy's tubercle similar to the technique described by Claes $^{15}$ in 2013 . However, an interference screw was used for femoral fixation.

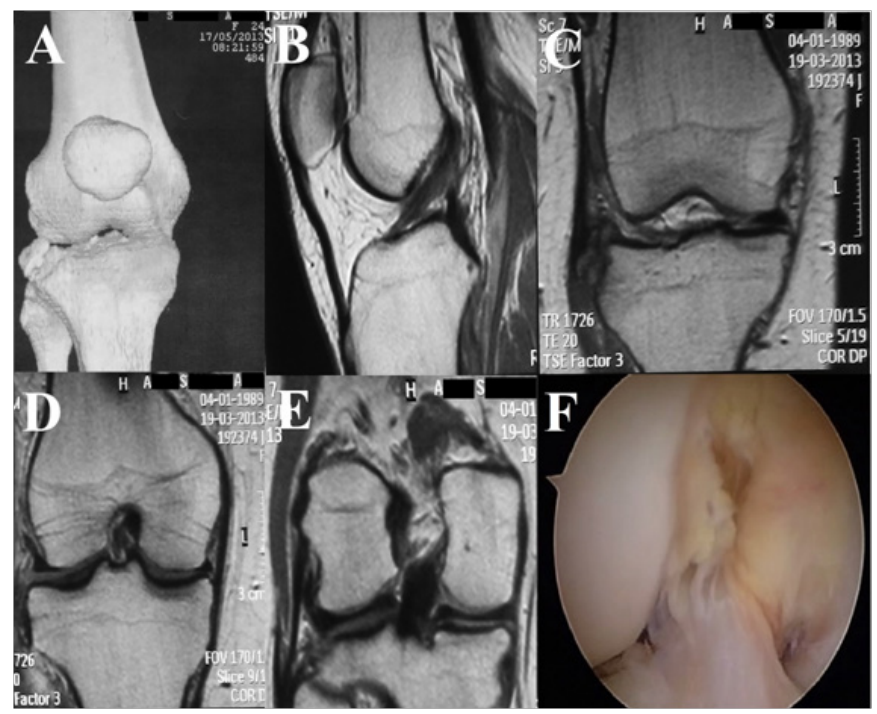

Figure 2 (A) CT with 3D reconstruction demonstrating the Segond fracture; (B) Sagittal MRI showing an intact ACL; (C) Ccoronal MRI showing the Segond fracture; (D) Coronal MRI showing an intact MCL; (E) Coronal MRI showing an intact posterolateral corner; (F) Arthroscopic view showing an intact ACL.

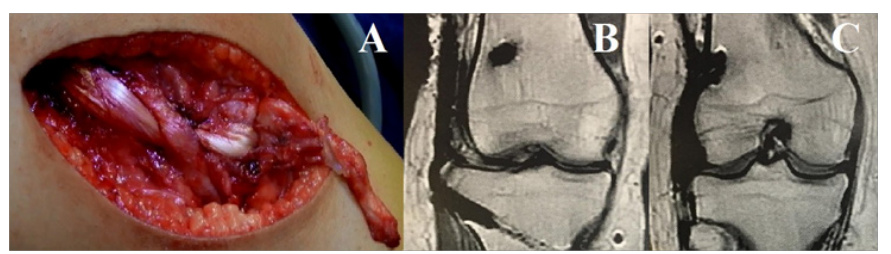

Figure 3 (A) Anterolateral ligament reconstructed deeper collateral lateral ligament; (B) Site of tibial fixation of the graft; (C) Site of femoral fixation of the graft.

A $10 \mathrm{~mm} \times 15 \mathrm{~cm}$ strip of the ITB was prepared maintaining its distal attachment at the Gerdy's tubercle. Its free end was prepared with Krakow sutures using Ethibond 2 (Ethicon, Somerville, NJ, USA). For the femoral fixation, an $8 \mathrm{~mm}$ diameter tunnel was drilled at the most isometric femoral point described by Kurosawa et al. ${ }^{16}$ for ACL extra-articular reconstruction. The graft was routed deeply to the lateral collateral ligament (LCL) according to the Cooker-Arnold technique. ${ }^{16}$ An interference screw BIORCI HA $8 \mathrm{~mm}$ x 35mm (Smith $\&$ Nephew, Inc, Andover, MA, USA) was used to fix the graft with the knee at $45^{\circ}$ of flexion in neutral rotational. During the stability evaluation tests, it was noticed a graft rupture at the femoral tunnel aperture. The femoral interference screw was retrieved and the remaining graft at the tunnel was removed. The hamstrings were harvested. A $7 \mathrm{~mm}$ quadruple semi-tendinosis and gracilis graft was prepared. An Endobutton CL Ultra (Smith \& Nephew, Inc, Andover, MA, USA) was used for tibial fixation at the site of the avulsion. The graft was routed deeply to the LCL. It was fixed at the femur using the previous tunnel and the retrieved interference screw with the knee at $45^{\circ}$ of flexion in neutral rotational. The ITB strip previously removed was sutured to the hamstrings graft. Final stability evaluation tests showed negative pivot-shift, negative Lachman and negative anterior drawer test. At two years follow-up, the patient presented no givingaway episodes and a good Lysholm score of 82 points (Figure 3).

\section{Discussion}

The French surgeon Paul Ferdinand Segond originally described the Segond fracture in 1879 through their biomechanical cadaver's experiments. ${ }^{1}$ Claes et al. ${ }^{6}$ demonstrated that the possible structure responsible for bone avulsion in Segond fractures is the anterolateral ligament. The classic mechanism description for this injury is a varus stress applied to a partially flexed and internally rotated knee stressing the anterolateral capsule. ${ }^{2}$ The patient on this report was not able to accurately describe its trauma.

An important finding was the positive ACL tests in the presence of an intact ACL when compared to the normal side. Although the drawer test and Lachman test were interpreted as nearly normal presenting a firm end point, the pivot-shift was rated abnormal. The anterior drawer and Lachman tests findings probably correspond just to anterolateral knee instability and not a true anterior translation. While it is possible to find Segond fracture reports without ACL rupture in children and adolescents ${ }^{3}$ this injury is considered pathognomonic of ACL lesion in adults. ${ }^{5}$

Some Segond fracture studies report associated ACL rupture in $75 \%$ to $100 \%$ and associated meniscal tears in $53 \%$ to $75 \% .^{6,17,18}$ In addition, Gottsegen et al. ${ }^{2}$ DeLee et al. ${ }^{18}$ reported the Segond fracture combined to popliteal tendon avulsion and iliotibial band avulsion. Wharton et al. ${ }^{3}$ published a case report in which the Segond fracture was combined to posterolateral ligament injury without ACL rupture in an adult. To the best of the author's knowledge, this is the first report of an isolated Segond fractures in an adult, not combined to other ligament injuries. The surgery was performed in 2013. Several extra-articular ACL reconstruction techniques exist for an ACL injury model. ${ }^{19}$ The authors utilized the femoral isometric point suggested by Kurosawa et al. ${ }^{16}$ and the final aspect of the reconstruction was similar to the ALL reconstruction technique proposed by Claes ${ }^{15}$ at 2013.

The ITB graft rupture at the femoral tunnel aperture complication can be related to some risk factors: interference screw fixation, killer turn, ITB graft thickness, increased cortical bone stiffness at the methaphysis/diaphysis transition area. Some suggestions to avoid this complication are using other fixation methods, modify the femoral tunnel angulation reducing the killer turn, use other grafts or widen the ITB strip harvest to $15 \mathrm{~mm}$. Recent studies demonstrated that ALL has an approximate maximum force of $200 \mathrm{~N}$, similar to the medial patellofemoral ligament. Excessive stress on the graft may cause graft failure, range of motion limitation and overconstraing of the lateral compartment of the knee. ${ }^{20}$

Currently, extra-articular reconstruction techniques specifically addressing the ALL are becoming less invasive and can rely on radiographic parameters. ${ }^{20-23}$ At present, our preferred surgical 
technique for ACL combined to ALL reconstruction is a minimally invasive approach using interlinked hamstrings graft. A triple semitendinosus is used for the ALC and a double gracilis is used for the ALL. Both grafts are fixed with interference screws. ${ }^{24}$ Due to the close relationship between the Segond fracture and ACL lesion, combined ACL and anterolateral complex lesions could be considered a Segond-like lesion.

\section{Conclusion}

The Segond fracture can occur as an isolated lesion causing instability, without the association of other ligaments injury, in the adult. It is not always pathognomonic of an ACL lesion. Isolated extra-articular ACL reconstruction could restore stability to an isolated Segond fracture.

\section{Acknowledgements}

We thank Dr. Camilo Helito for the motivation and support.

\section{Conflict of interest}

Authors declare that there is no conflict of interest.

\section{References}

1. Segond P. Les épanchements sanguis du genou par entorse. Progres Med. 1878;7:297-299,319-321,340-341.

2. Gottsegen CJ, Eyer BA, White EA, et al. Avulsion fractures of the knee: imaging findings and clinical significance. Radiographics. 2008;28(6):1755-1770.

3. Wharton R, Henckel J, Bhattee G, et al. Segond fracture in an adult is not pathognomonic for ACL injury. Knee Surg Sports Traumatol Arthrosc. 2015;23(7):1925-1928.

4. Arneja SS, Furey MJ, Alvarez CM, et al. Segond Fractures. Not Necessarily Pathognemonic of Anterior Cruciate Ligament Injury in the Pediatric Population. Sports Health. 2010;2(5):437-439.

5. Reddy D, Alexander R, Hussain WM, et al. Adolescent Segond fracture with an intact anterior cruciate ligament. Orthopedics. 2012;35(7):1112-1115.

6. Claes S, Luyckx T, Vereecke E, et al. The Segond fracture: a bony injury of the anterolateral ligament of the knee. Arthroscopy. 2014;30(11):1475-1482.

7. Vincent JP, Magnussen RA, Gezmez F, et al. The anterolateral ligament of the human knee: an anatomic and histologic study. Knee Surg Sports Traumatol Arthrosc. 2012;20(1):147-152.

8. Helito CP, Miyahara HdS, Bonadio MB, et al. Anatomical study of the anterolateral knee ligament. Rev Bras Ortop. 2013;48(4):368-373.

9. Helito CP, Demange MK, Bonadio MB, et al. Anatomy and histology of the knee anterolateral ligament. Orthop J Sports Med. 2013;1(7):2325967113513546.
10. Watt VL, Khan M, Rothrauff BB, et al. The structure and function of the anterolateral ligament of the knee: a systematic review. Arthroscopy. 2015;31(3):569-582.

11. Helito CP, Bonadio MB, Soares TQ, et al. The meniscal insertion of the knee anterolateral ligament. Surg Radiol Anat. 2015;38(2):223-228.

12. Claes S, Bartholomeeusen S, Bellemans J. High prevalence of anterolateral ligament abnormalities in magnetic resonance images of anterior cruciate ligament-injured knees. Acta Orthop Belg. 2014;80(1):45-49.

13. Irrgang DJJ, Ho H, Harner CD, et al. Use of the International Knee Documentation Committee guidelines to assess outcome following anterior cruciate ligament reconstruction. Knee Surg Sports Traumatol Arthrosc. 1998;6(2):107-114.

14. Peccin MS, Ciconelli R, Cohen M. Questionário específico para sintomas do joelho "Lysholm Knee Scoring Scale": tradução e validação para a língua portuguesa. Acta ortop bras. 2006;14(5):268-272.

15. Steven Claes. The Pivot Shift Unraveled: Why We Disagree With Dr. Fu. 2015.

16. Kurosawa H, Yasuda K, Yamakoshi K, et al. An experimental evaluation of isometric placement for extra-articular reconstructions of the anterior cruciate ligament. Am J Sports Med. 1991;19:384-388.

17. Marcacci M, Zaffagnini S, Muccioli MGM, et al. Arthroscopic intra-and extra-articular anterior cruciate ligament reconstruction with gracilis and semitendinosus tendons: a review. Curr Rev Musculoskelet Med. 2011;4(2):73-77.

18. Delee JC, Riley MB, Rockwood CA. Acute posterolateral rotatory instability of the knee. Am J Sports Med. 1983;11(4):199-207.

19. Rezende FC, Moraes DVY, Martimbianco AL, et al. Does Combined Intraand Extra articular ACL Reconstruction Improve Function and Stability? A Meta-analysis. Clin Orthop Relat Res. 2015;473(8):2609-2618.

20. Cottet SB, Thaunat M, Freychet B, et al. Outcome of a Combined Anterior Cruciate Ligament and Anterolateral Ligament Reconstruction Technique With a Minimum 2-Year Follow-up. Am J Sports Med. 2015;43(7):1598-1605.

21. Helito CP, Demange MK, Bonadio MB, et al. Radiographic landmarks for locating the femoral origin and tibial insertion of the knee anterolateral ligament. Am J Sports Med. 2014;42(10):2356-2362.

22. Kennedy MI, Claes S, Fuso FA, et al. The Anterolateral Ligament: An Anatomic, Radiographic and Biomechanical Analysis. Am J Sports Med. 2015;43(7):1606-1615.

23. Helito CP, Bonadio MB, Gobbi RG, et al. Combined Intra and Extraarticular Reconstruction of the Anterior Cruciate Ligament: The Reconstruction of the Knee Anterolateral Ligament. Arthrosc Tech. 2015;4(3):e239-e244.

24. Ferreira MC, Zidan FF, Miduati FB, et al. Reconstruction of anterior cruciate ligament and anterolateral ligament using interlinked flexors Technical note. Rev Bras Ortop. 2016;51(4):466-470. 